\title{
Iodination - the need to enforce quality assurance
}

\section{Channa Ratnatunga}

University of Peradeniya, Peradeniya, Sri Lanka.

Correspondence: Prof. Channa Ratnatunga

e-mail: channasurg@yahoo.com

D. https://orcid.org/0000-0001-5101-892X
Iodination of salt was made compulsory in Sri Lanka by the Food Act no 26 of 1980. After some delay the government decided to implement the iodination of salt in 1995 .

The Medical Research Institute (MRI) helped by the WHO, has monitored the effects of iodination by conducting surveys on school children nationwide every five years $(1-4)$ beginning from 20002001. The requirement of iodine (as iodate) at consumer level was brought down from $25 \mathrm{ppm}$ at the beginning to $15 \mathrm{ppm}$ in 2005 , as surveys monitoring urinary iodine content in the sampled children, showed a median concentrations above the target level $100 \mu \mathrm{g} / \mathrm{L}$.

They conclude after their most recent survey i.e. 2016, that the iodine content of salt packs available to the public are not 'Iodine content-wise' uniform throughout the different provinces of Sri Lanka. This was true between brands and within the same brand; an observation documented in each monitoring report in the last two decades (1-4). In consequence, this was responsible partially to the non-uniformity of urinary iodine content in the children of the different provinces. Fortunately, the urinary concentrations observed are all below the WHO recommended figures i.e. $300 \mu \mathrm{g} / \mathrm{L}$. Paradoxical though it may sound, population demographics necessitates it to be so. I will explain.

As the intent was initially to prevent goitre, we need to review what's happened to the 'goitre-scape' since instituting iodination of salt, now almost two and a half decades ago. The data presented by the MRI on these surveys suggest, within the last two decades, the children who were the 'at risk' population to get goitre, have shown a regression of both the prevalence of goitre and its size in all provinces; Uva province being the straggler. The surveys showed that in children (6 - 12 years) an overall (national) $\%$ incidence of grade 1 goitre has regressed from 18.2 to 1.5 and grade 2 goitre from 0.8 to 0.4 between 2000 (1) and 2016 (4) respectively, in consequence.

However, audits of patients attending surgical clinics in some formerly endemic districts have a slightly different picture (5). No doubt, they are older and selected, but need to be taken to account. Regression of nodular goitre prevalence in this older age groups began around seven years later and diffuse goitre thirteen years later. However the presenting grades (size) too, also showed regression.

These previously endemic districts, harboured an elderly population, especially females with multinodular goitres that have foci of autonomic activity. After iodination, the prevalence of hyperthyroidism $(6,7)$ has shown significant increase in all adult age groups with multi-nodular goiter, that too directly proportional to their age. So placing such elderly subjects at risk of cardiac fibrillation and consequent possible thrombo-embolism especially to the central nervous system (stroke), osteoporotic fractures etc. is not advisable.

The iodine content of salt packs, exceeding regulations has been shown to have increased the prevalence of autoimmune thyroiditis (AIT) $(8,9)$ leading to goitre (8) and hypothyroidism (which if gone undetected, with effects on the elderly, on pregnant patients and on the academic performance of schoolchildren). Less commonly hyperthyroidism can also occur. 
A nationwide (except north and east) study done in 2007 - 2008 on individuals above the age of ten, revealed an AIT (clinical-serological-cytological) prevalence of $19-20 \%$ of individuals sampled (8) with the median urinary concentration being 235 $\mu \mathrm{g} / \mathrm{L}$. The Northern and North-Central Provinces have consistently shown the highest concentrations of urinary iodine $(1-4,9,10)$ in both adults and children. Further, North Central province harboured the pocket with the highest prevalence of goitre (all age groups) in a study in 2007 (11). In a very recent study of AIT in the Northern Province, a high prevalence (approx. and 40\%) of goitres having AIT, with its associated hormonal complications have been reported. Could AIT be also responsible for this increase in goitres? (12).

Salutary effects on the histological type of carcinoma of the thyroid (papillary type prevalence increasing as opposed to the anaplastic type) has certainly reduced morbidity and mortality of this scourge (13). Perusal of local Cancer Registry statistics reveal an increasing prevalence of papillary thyroid cancer, which though is less virulent and manageable has its own issues. Thyroid carcinoma, which was the fifth most common malignancy in this country among females in 2000 became the third in 2011 and the second most common in 2014 among females (14). A high prevalence of papillary thyroid cancer was found in Iceland and thought to be due to an excessive iodine intake (15).

This highlights the need to keep the urinary iodine content optimal, i.e. the iodine content of salt packs optimal, within prescribed limits throughout all provinces. The revelation that none of the salt manufacturer's had written instructions on the process of iodisation, i.e. the quantities that need to be added, is an alarming revelation (8). Besides details of manufacture, its packaging, storage must be supervised at the factory and retailer level. The consumer should be instructed regarding loss of iodine by washing or storage near a fireplace. At present, consideration is not given to the provinces with high dietary iodine like those in the dry zone. Has the time come for PHI of provincial councils together with the Sri Lanka Standards Institution, to act re-supervising factories, on the production, based on selective needs of the individual provinces? Iodine excess is in itself a health risk.

\section{References}

1. Renuka Jayatissa. Iodine content of salt and the iodine deficiency status of children in Sri Lanka. Published by the Medical Research Institute and the Department of Health Services Sri Lanka 2001.

2. Renuka Jayatissa. Iodine nutrition status in Sri Lanka 2005, Published by Medical Research Institute and Department of Healthcare and Nutrition 2006 with sponsorship of UNICEF.

3. Renuka Jayatissa, Gunatileke MM. Third National Survey on Iodine Deficiency Status in Sri Lanka 2010, Published by Medical Research Institute in collaboration with the UNICEF.

4. Renuka Jayatissa, Fernando DN, Himali Herath. Iodine Deficiency Status in Sri Lanka 2016. Fourth National Survey. Published by Medical Research Institute in collaboration with the UNICEF and the World Food Care programme, Ministry of Health and Nutrition and Indigenous Medicine.

5. Ratnatunga PCA, Dassanayaka R, Kumari AN, Aglawatta $\mathrm{AB}$, Galketiya KB, Ratnatunga NVI. Pattern of clinical benign euthyroid goitre in a tertiary care center in the Central Province of Sri Lanka from 1981-2011. Ceylon Medical Journal, 2016; 61(4): 176-180. DOI: http://doi.org/10.4038/cmj.v61i4.8385.

6. Wikramanayake T. Iodised salt and hyperthyroidism. Ceylon Medical Journal, 2014; 45(4):173-4. DOI: http://doi.org/10.4038/cmj.v45i4.6725.

7. Ratnatunga PCA, Galketiya KB, Dassanayake R, Kumari, Agalawatte GB, Ratnatunge NVI, Ratnatunga CN. Iodination and its effect on hyperthyroidism. Sri Lanka Journal of Medicine, 2017; 25(2): 3-10. DOI: http://doi.org/10.4038/sljm.v25i2.19.

8. Fernando RF, Chandrasinghe PC, Pathmeswaran AA. The prevalence of autoimmune thyroiditis after universal salt iodisation in Sri Lanka. Ceylon Medical Journal, 2012; 57(3); 116-119. DOI: http://doi.org/10.4038/cmj.v57i3. 4702 .

9. Wijeyaratne CN, Jayasinghe A, DGH de Silva, Parkes AB, Lazarus JH, Premawardhana LDKE. Iodine prophylaxis, goitre and thyroid autoimmunity in Sri Lanka. Ceylon Medical Journal, 2005; 50(1): 20-23. DOI: http://doi.org/ 10.4038/cmj.v50i1.1585. 
10. Jayatissa R, Gunathilaka M. Fernando DN. Iodine nutrition status among schoolchildren after salt iodisation. Ceylon Medical Journal, 2009; 50(4): 144-48. DOI: http://doi.org/10.4038/cmj.v50i4.1403.

11. Fernando R, Pathmeswaran A. Pinto MDP. Epidemiology of goitre in Sri Lanka in the post-iodization era. Ceylon Medical Journal, 2015; 60(2): 41-44. DOI: http://doi.org/10.4038/cmj.v60i2.8150.

12. Rajendra $\mathrm{S}$, Chronic autoimmune thyroiditis: a challenging clinical entity in surgical practice. Sri Lanka Journal of Surgery, 2019; 37(4): 3-10. DOI: http://doi.org/ 10.4038/sljs.v37i4.8656.
13. Ratnatunga PCA, Amarasinghe S. Ratnatunga NVI. Changing Patterns of Thyroid Cancer In Sri Lanka. Has the Iodination Programme Helped?. Ceylon Medical Journal, 2003; 48(4): 125-128. DOI: http://doi.org/10.4038/cmj. v48i4.3329.

14. Government: Cancer Registry Statistics Sri Lanka Online.

15. Williams ED, Doniach I, Bjarnason O, Michie W. Thyroid cancer in an Iodine Rich area. Cancer, 1977; 39(1): 215-22. 